\title{
Study on removal of radioactive material from marine and lake mud
}

\author{
Keiichiro Shibata $^{\text {i) }}$, Hidenori Yoshida ${ }^{\text {ii) }}$ and Naomichi Matsumoto ${ }^{\text {iii) }}$
}

\begin{abstract}
i) Grad. Student, Div. Safety Systems Constr. Eng., Kagawa University, 2217-20 Hayashicho, Takamatsu, Kagawa, 761-0396, JAPAN
ii) Professor, Dept. Safety Systems Constr. Eng., Kagawa University, 2217-20 Hayashicho, Takamatsu, Kagawa, 761-0396, JAPAN iii) Technical staff, Faculty of Engineering, Kagawa University, 2217-20 Hayashicho, Takamatsu, Kagawa, 761-0396, JAPAN
\end{abstract}

\begin{abstract}
The serious nuclear disaster in the Fukushima Daiichi nuclear energy plant of the Tokyo Electricity Power Company was occurred by the tsunami which was caused by the Great East Japan Earthquake on March 11, 2011. The radioactive materials emitted by the disaster were widely diffused in and around Fukushima prefecture including the Pacific Ocean by wind, rain and a flow of river. It can't be always said that there is no risk of the condensation of radioactive materials in human's body by ecological chain if fish take in radiation in the ocean contaminated by the radioactive materials. However the effective decontamination methods of the radioactive materials are not developed and the decontamination is less-advanced. The establishment of a new decontamination method is urgent need and indispensable in light of disadvantageous effect on ecological system. Thus, in this study, it is aimed to establish a new decontamination technology of radioactive materials deposited on seabed or lake bed. In particular, the new adsorption material which can adsorb radioactive materials is developed and the new method which can move them from the bottom sediment is proposed. The results obtained from various tests with or without the water circulation and the adsorption material indicate that the water circulation is effective and that the adsorption material has a great deal of potential in the decontamination of radioactive materials. It is expected that the proposed method and the developed adsorption material are efficient to remove radioactive materials from seabed or lake bed when they are expansively applied to the real decontamination.
\end{abstract}

Keywords: aeration, adsorbent, decontamination, radioactive material

\section{INTRODUCTION}

The serious nuclear disaster in the Fukushima Daiichi nuclear energy plant of the Tokyo Electricity Power Company was occurred by the tsunami which was caused by the Great East Japan Earthquake on March 11, 2011. The decontamination of radioactive materials which were emitted and spread by the disaster is urgent business(cf. Ishiyama, 2013). However an efficient and effective technique of decontamination has not been established.

As for a past study in terms of decontamination in hydrosphere, for example, there is the method in which the polluted mud is dredged. Concretely speaking, the bottom deposit is resuspended by a jet blast. The resuspended solids which is stirred up by the jet blast is collected in fluid. At the same time, aerobic is promoted by the stirring. However, in this method, there is the view that the radioactive materials can be diffused widely in hydrosphere. Additionally, it will be difficult to secure intermediate storage facilities enough for hydrosphere.
Basically, in a factual issue, the present situation is that the decontamination is nowhere in sight. The decontamination situation for marine and lake is more or less same as that for land. Especially, in hydrosphere, it is possible that human take in radioactive materials by ecological chain in case ecological system is exposed to radiation. If marine and lake were polluted by radioactive materials, the decontamination for them should be urgent. Thus, in this study, the decontamination method for radioactive materials without dredging mud in marine and lake is proposed with keeping in mind of the shortage of the intermediate storage facilities for the sand polluted by radioactive materials.

\section{EXPERIMENT AND ANALYSIS}

There are two issues in terms of the decontamination in hydrosphere, the non-proliferation and volumereduction of radioactive materials. In this study, the new adsorption material which can adsorb radioactive 
materials is developed and the new method which can move them from the bottom sediment is proposed so as to solve the issues. To be more precise, the new adsorption sheet which consists primarily of hydroxyapatite (HAp) is developed and the aeration is employed for the convection of fluid (cf.Shigeta, 2013). The adsorption tests by which cesium and strontium are adsorbed are conducted with the developed sheet and the proposed method to examine their validity and availability.

First, Toyoura sand is laid at the bottom of cylindrical chamber to simulate the decontamination in marine or lake. In the test, $200 \mathrm{~g}$ of Toyoura sand which has uniform size of grains is utilized so as to keep the reproducibility of tests. Secondly, $38.1 \mathrm{mg}$ of cesium or $5.0 \mathrm{mg}$ of strontium is added into the sand, and the adsorption sheet and the convection device are set on the sand (see Fig.1). Subsequently, pure water is poured into the chamber to simulate the decontamination in lake, and sodium chloride solution is poured into the chamber to simulate the decontamination in marine. The sodium chloride is $3 \%$ concentration in the solution to be close to that in seawater. As for specimens, three types of the specimen are prepared to evaluate the validity and availability of contamination; one is the specimen in which only the sheet is set, another is the specimen in which the sheet and the convective device are set, and the other is the specimen in which nothing is set. And they are left for a given length of time. After the tests, the cesium or strontium contained in Toyoura sand is extracted by washing the sand. For the extracted water solution, cesium is analyzed by AAS (Atomic Absorption Spectrometer) to measure its remained amount of the pure water, and the strontium is analyzed by ICP-AES (Inductively-coupled Plasma Atomic Emission Spectrometry) to measure its remained amount of the sodium chloride solution. The availability of convective method and adsorption sheet are examined by the comparison of remained amount of three type specimens.

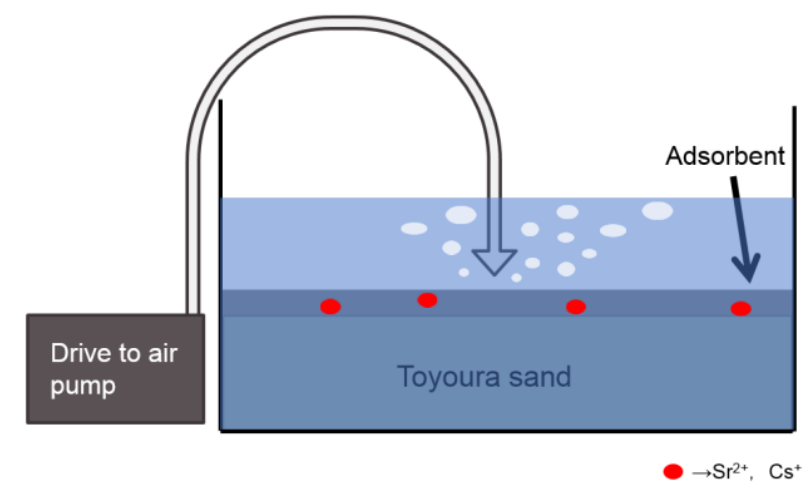

Fig.1. Schematic of aeration test.

\section{TEST FOR CESIUM ADSORPTION}

The results of the immersion tests in which the adsorption performance of cesium by the HAp sheet is examined with changing the immersion time are shown and are discussed. In the tests for cesium, only pure water is utilized as for the solution. The remained amount of cesium in the water after 4 weeks and 13 weeks from the start of immersion are shown in Table 1. Figs. 2 and 3 show the ratio of the remained amount of cesium to the initial additive amount of cesium after 4 weeks and 13 weeks from the start of immersion, respectively. The ratio is decreased during 9 weeks of their interval. However, not only the test with both the sheet and the aeration but also the test with neither of them show the similar tendency in terms of the decrease of the ratio. Such a phenomenon as the decrease of ratio may be caused by the change of temperature and humidity. Since the reason why the remained amount of cesium in the water for the specimen left uncontrolled is decreased with time is unclear, the effectiveness and availability of the sheet or the aeration are not discussed. Hereafter, the additional tests such as the increase of specimens under varied conditions and the extension of immersion time are required.

Table 1. Test results for cesium

\begin{tabular}{|l|r|r|r|r|}
\hline & \multicolumn{2}{|l|}{4 weeks } & \multicolumn{2}{l|}{13 weeks } \\
\cline { 2 - 5 } & $\begin{array}{l}\text { Remained } \\
\text { amount } \\
(\mathrm{mg})\end{array}$ & $\begin{array}{l}\text { Residual } \\
\text { ratio } \\
(\%)\end{array}$ & $\begin{array}{l}\text { Remained } \\
\text { amount } \\
(\mathrm{mg})\end{array}$ & $\begin{array}{l}\text { Residual } \\
\text { ratio } \\
(\%)\end{array}$ \\
\hline $\begin{array}{l}\text { No aeration } \\
\text { no adsorbent }\end{array}$ & 14.76 & 38.74 & 11.70 & 30.70 \\
\hline $\begin{array}{l}\text { No aeration } \\
\text { use } \\
\text { adsorbent }\end{array}$ & 15.85 & 41.61 & 11.87 & 31.15 \\
\hline $\begin{array}{l}\text { Use aeration } \\
\text { use } \\
\text { adsorbent }\end{array}$ & 12.42 & 32.60 & 10.44 & 27.40 \\
\hline
\end{tabular}

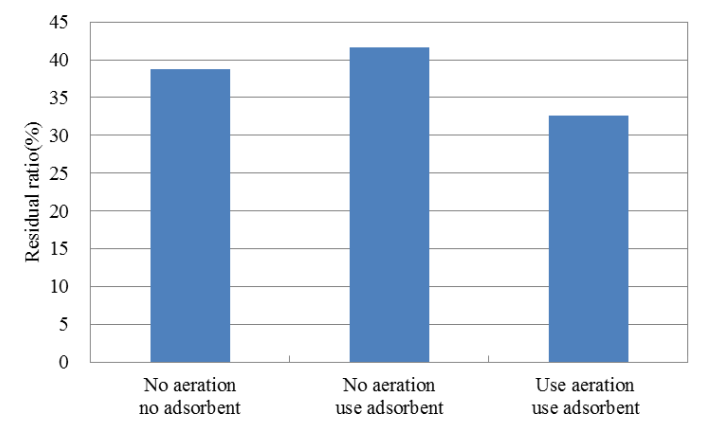

Fig.2. Residual ratio of cesium for 4 weeks. 


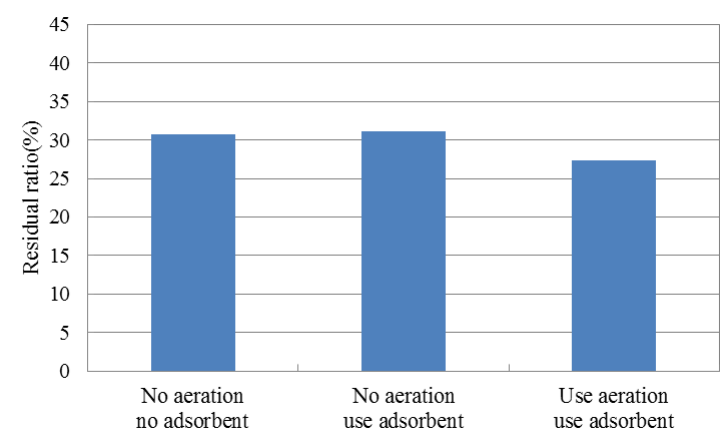

Fig.3. Residual ratio of cesium for 13 weeks.

\section{TEST FOR STRONTIUM ADSORPTION}

The results of immersion tests in which the adsorption performance of strontium by the HAp sheet is examined with changing the immersion time are shown and are discussed. In the test for strontium, pure water and sodium chloride solution are utilized as the solution. The tests time are 1 week and 4 weeks. The other conditions of strontium adsorption test are same as those of cesium adsorption test. The remained amount of strontium in the solution after 4 weeks and 13 weeks from the start of immersion are shown in Tables 1 and 2. Figs. 4 and 5 show the ratio of the remained amount of strontium to the initial additive amount of solution after 1week and 4 weeks from the start of immersion, respectively. According to the figures, the residual ratio of strontium is relatively low in the case of 4 weeks emersion test with pure water. On the other hand, that is relatively low in the case of 1 week emersion test with sodium chloride solution. As the reason, it is possible that the strontium which firmly adhered to the soil is liberated from the soil into the solution. This phenomenon occurs in the case of abundant $\mathrm{Na}$ ion $\left(\mathrm{Na}^{+}\right)$. Additionally, the convective method may have the space to be improved. The strontium liberated from soil passes through the HAp sheet when the aeration is performed on the sheet. However, the strontium liberated into sodium chloride solution has less chance to pass through the HAp sheet. Therefore, it is needed to exam the setting method for the HAp sheet so as to adsorb cesium or strontium in not only soil but also solution effectively.
Table 1. Test results for strontium for 1 week

\begin{tabular}{|l|r|r|r|r|}
\hline & \multicolumn{2}{|l|}{ Pure water } & \multicolumn{2}{l|}{ Sodium chloride fluid } \\
\cline { 2 - 5 } & $\begin{array}{l}\text { Remained } \\
\text { amount } \\
(\mathrm{mg})\end{array}$ & $\begin{array}{l}\text { Residual } \\
\text { ratio } \\
(\%)\end{array}$ & $\begin{array}{l}\text { Remained } \\
\text { amount } \\
(\mathrm{mg})\end{array}$ & $\begin{array}{l}\text { Residual } \\
\text { ratio } \\
(\%)\end{array}$ \\
\hline $\begin{array}{l}\text { No aeration } \\
\text { no adsorbent }\end{array}$ & 2.79 & 55.74 & 3.29 & 65.81 \\
\hline $\begin{array}{l}\text { No aeration } \\
\text { use } \\
\text { adsorbent }\end{array}$ & 2.42 & 48.47 & 2.41 & 48.20 \\
\hline $\begin{array}{l}\text { Use aeration } \\
\text { use } \\
\text { adsorbent }\end{array}$ & 2.19 & 43.86 & 2.05 & 40.93 \\
\hline
\end{tabular}

Table 2. Test results for strontium for 4 weeks

\begin{tabular}{|l|r|r|r|r|}
\hline & \multicolumn{2}{|l|}{ Pure water } & \multicolumn{2}{l|}{ Sodium chloride fluid } \\
\cline { 2 - 5 } & $\begin{array}{l}\text { Remained } \\
\text { amount } \\
(\mathrm{mg})\end{array}$ & $\begin{array}{l}\text { Residual } \\
\text { ratio } \\
(\%)\end{array}$ & $\begin{array}{l}\text { Remained } \\
\text { amount } \\
(\mathrm{mg})\end{array}$ & $\begin{array}{l}\text { Residual } \\
\text { ratio } \\
(\%)\end{array}$ \\
\hline $\begin{array}{l}\text { No aeration } \\
\text { no adsorbent }\end{array}$ & 2.58 & 51.56 & 3.76 & 75.29 \\
\hline $\begin{array}{l}\text { No aeration } \\
\text { use } \\
\text { adsorbent }\end{array}$ & 1.98 & 39.66 & 3.69 & 73.82 \\
\hline $\begin{array}{l}\text { Use aeration } \\
\text { use } \\
\text { adsorbent }\end{array}$ & 1.62 & 32.47 & 2.85 & 57.00 \\
\hline
\end{tabular}

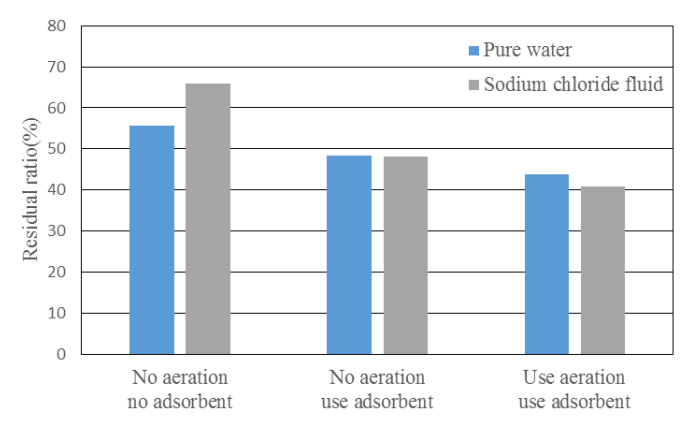

Fig.4. Residual ratio of strontium for 1week.

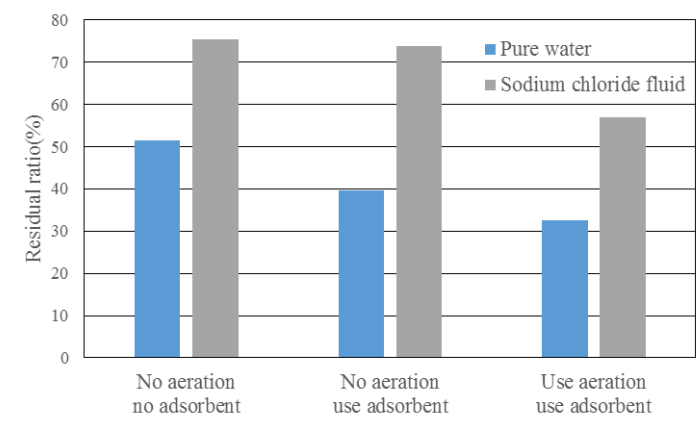

Fig.5. Residual ratio of strontium for 4 weeks. 


\section{CONCLUSIONS}

In this study, a new decontamination method is proposed without dredging mud in marine and lake with considering the shortage of the intermediate storage facilities for the sand polluted by radioactive materials. To examine the validity and availability of the developed material and the proposed method, the adsorption tests by which cesium and strontium are adsorbed by the developed adsorption sheet are conducted. From the test results, it is found that the difference between the residual ratio of strontium in the tests with the HAp sheet and the convective device and the residual ratio of strontium in the test with nothing is larger than the difference of the residual ratios of cesium in the both tests. From here onwards, the following two knowledge are obtained. One is that most of strontium are existed in the fluid; pure water and sodium chloride solution. Another is that cesium is strongly adhering to Toyoura Sand. As has already stated, the possibility that the strontium is not effectively adsorbed in the experimental environment in this study is not denied. Therefore, the additional issues such as the extension of immersion time and the increase of test specimen should be examined in near future. While at the same time, the settings of the HAp sheet should be also discussed. More to the point, in this study, the number of test is not enough since the longest terms of immersion test are 13 weeks for cesium and 4 weeks for strontium. In concrete terms, the longer immersion test, 13, 26 and 52 weeks immersion tests, are required.

This work was supported by JSPS KAKENHI Grant Number 24520507.

\section{REFERENCES}

1) Fisheries Agency (2015): The report for examination of radioactive material in fishery product, $23-28,46-50$ (in Japanese).

2) Hydrographic and Oceanographic Department Japan Coast Guard (2014): Report of Radioactivity Surveys, ISSN 0910044X, 3-11 (in Japanese).

3) Ishibashi, M., Ueda, S. and Yamamoto, Y. (1969): The Contents of Strontium and Strontium-90 in Shallow-water Deposits, Journal of the Oceanographical Society of Japan, 25(5), 233-238 (in Japanese).

4) Ishiyama, S. and Yamaguchi, K. (2013): Investigation of Actual Condition of Contaminated Soil in Regulation Pond Conducted by Underwater Radiation Measuring Instrument Installed in Remotely-Operated Vehicle(Second Field Test in Fukushima), The Japan Society of Mechanical Engineers, 79(799), 269-276 (in Japanese).

5) Ministry of the Environment (2013): Introduction of the established social work for the decontamination, 5 (in Japanese).

6) National Maritime Research Institute, Institute of Industrial Science of Tokyo University, Institute of Nature and Environmental Technology of Kanazawa University (2014):
Research enterprise on comprehending distribution condition of radioactive material in marine area, 28-36 (in Japanese).

7) Shigeta, H., Enomoto, T. and Sugihara, T. (2013): Development of a Medical Grinding Tool Considering Material Properties of Wet Bone for Minimally Invasive Surgery, The Japan Society of Mechanical Engineers, 79(804), 258-259 (in Japanese).

8) Tanaka, Y., Miura, K., Minowa, N., Toda, M. and Hasegawa, T. (2014): Sorption of nonradioactive- and radioactivecesium and nonradioactive strontium with an agent synthesized from amorphous silica and hydrated lime (CSH) recovered from advanced treatment reactor of swine wastewater, Japanese Society of Animal Science, 85(2), 179185 (in Japanese). 